\title{
The impact of attendance on first-year study success in problem-based learning
}

\author{
Patrick Bijsmans $^{1} \cdot$ Arjan H. Schakel $^{1}$
}

Published online: 27 February 2018

(C) The Author(s) 2018. This article is an open access publication

\begin{abstract}
The literature on first-year study success has identified a host of factors that may affect a student's chances of succeeding, ranging from personal circumstances to educational environment. One of the factors that often emerges in this context is (non-)attendance of classes, lectures and tutorials. Intuitively, one would expect this to be all the more important in programmes that employ a student-centred and interactive approach to learning, such as problem-based learning. Interestingly, there is little dedicated research that looks into the importance of (non-)attendance in such a learning environment. This article addresses this gap in the literature by looking at the effect of (non-)attendance on the study success of three cohorts of Maastricht University's Bachelor in European Studies (annual intake of 325-350 students). Controlling for a range of factors, we find that attendance matters for several measures of study success and also for the committed and participating student.
\end{abstract}

Keywords Attendance · First-year experience $\cdot$ Higher education · Problem-based learning · Study success

\section{Introduction}

The first year of studies is of key importance in determining students' chances of completing their studies in higher education. Many new students struggle with the transition from secondary school to university and have difficulties adapting to academic norms and expectations (e.g. Briggs et al. 2012; Bruinsma and Jansen 2009; Jansen et al. 2017). Class attendance is often identified as being important for students' persistence and results, with absenteeism seen as increasing the risk of dropout (e.g. Credé et al. 2010; Moore et al. 2003). In this context, Trotter and Roberts (2006, p. 382) stress the importance of stimulating "an

Patrick Bijsmans

patrick.bijsmans@maastrichtuniversity.nl

1 Department of Political Science, Faculty of Arts and Social Sciences, Maastricht University,

P.O. Box 616, 6200 MD Maastricht, The Netherlands 
ethos of attendance" as key in terms of integrating first-year students into academia (cf. Rau and Durand 2000).

In Dutch higher education, the first year is of particular importance. Students generally have to pass a minimum number of credits to be able to continue into the second year of their studies, the so-called binding study advice (BSA). This also applies to students enrolled in Maastricht University's Bachelor in European Studies (BA ES). This programme revolves around problem-based learning (PBL). Active student engagement is key to the success of PBL and, hence, one could argue that attendance is deemed to be crucial for effective student performance in PBL-based programmes (cf. Loyens et al. 2012, p. 419; Maurer 2015, p. 372).

Interestingly, despite an ample body of literature on attendance and study success, there is hardly any specific research into the PBL context (one exception: van Berkel and Schmidt 2000). Scholars appear to assume that attendance matters in PBL, just like it is common to assume that participation matters in such an environment. However, in practice these assumptions do not always hold. For instance, Remedios et al. (2008) show that silent students in active learning environments may still learn. Moreover, with the premises of PBL not always being uniformly applied in practice (Moust et al. 2005), there is a need to further study PBL practice, including the impact of attendance on study success.

Our research is aimed at addressing this gap in the literature. By assessing in how far students' (non-)attendance matters for first-year study success in the BA ES, we explore the question whether and to what extent attendance matters in a PBL teaching and learning environment. ${ }^{1}$ This article starts with a discussion of the literature on transition and firstyear experience and on the importance of attendance for study success. Next, we will shortly introduce the BA ES. This is followed by an overview of our research design. Subsequently, we will present our findings, which, as we will show below, suggest that attendance is even more important than expected.

\section{Transition and first-year experience}

The start of an academic career is challenging, with the transition from secondary school to university seen as an important phase (Coertjens et al. 2017; Kyndt et al. 2017) and the first year in higher education perceived as being especially "crucial" (Brahm et al. 2017). In the words of Bruinsma and Jansen (2009, pp. 100-101), "[t]he first year is especially important as it serves as an orientation to the remainder of the study and selects those students who are willing to persist". The range of factors that comes into play when transitions from secondary school to university and first-year study success are concerned is broad. Individual student characteristics such as age, gender, motivation, personality, secondary school performance and study skills play a role, as do issues related to the programme of study, such as curriculum design, educational environment, induction activities and social integration (e.g. Briggs et al. 2012; Trautwein and Bosse 2017; Trotter and Roberts 2006).

With governments aiming for greater access to higher education, while simultaneously requiring increased retention and completion, universities have to explore ways in which to

\footnotetext{
${ }^{1}$ We focus on the cohorts of 2012/2013, 2013/2014 and 2014/2015 for which a total of 1059 students were enrolled. We focus on a group of 650 students, excluding students who did not show up at all, dropped out during the academic year or did not participate in all examinations. In the analyses presented below, we further narrow down the group of 650 students to 548 students who passed the threshold of earning at least 42 out of 60 ECTS and 326 students who, additionally, attended the minimum required meetings for each course of the first year.
} 
ease transition and enhance first-year experience. Even though there are external factors beyond the control of universities (Leveson et al. 2013), they can take steps to create an environment in which students' chances of persisting increase. For instance, researchers have stressed that being part of a community is important for students to do well at university - this concerns both academic and social integration (e.g. Tinto 1997; Wilcox et al. 2005; Zhao and Kuh 2004). As such, fostering a supportive academic and social environment can increase students' belief in their own capacities and can help keep them motivated and engaged (Brahm et al. 2017; Korhonen et al. 2017; Tinto 2017).

Jansen and Suhre (2010) argue that an active learning environment is important for students' persistence, especially in their first year. Similarly, Tinto (2017, p. 263) argues that for students to see the relevance of topics and subjects, it is worth exploring the opportunities offered by "problem and project-based pedagogies that call for students to apply what they are learning to address meaningful problems". Indeed, active learning environments such as PBL, which are usually characterised by closer interaction with and between peers and academic staff, provide a community and give context to learning. PBL is a student-centred approach that presumes self-directed learning and relies on an active construction of knowledge in the context of specific problems. Learning is a collaborative process in which students discuss problems and literature, and exchange ideas and arguments (e.g. Loyens et al. 2012; Maurer 2015). Attending PBL tutorials as such may help induce a feeling of community, even when a student does not actively take part in discussions (Remedios et al. 2008).

\section{Attendance and study success}

Among the factors that often reoccur in research on first-year study success is attendance and non-attendance. Jansen and Suhre (2010) consider attending classes crucial for students to succeed. Similarly, Georg (2009, p. 657) notes that "limited class attendance" is one of the characteristics of students who might not persist. This perceived influence of attendance on study success is also reflected in a dedicated body of research.

Some question the effects of attendance on study results. For instance, in their study on the importance of attendance for academic performance of second-year medical students, Eisen et al. (2015) conclude that not attending active and engaged learning sessions had no negative effects on results. However, many other studies have concluded that there is a clear relationship between attending or not attending classes and study results (Bevitt et al. 2010; Moore et al. 2003; Woodfield et al. 2006). Most of these studies tend to look at one undergraduate programme, but Newman-Ford et al. (2008) studied the impact of attendance on results of first-year students in four undergraduate programmes at the University of Glamorgan and found significant effects in nearly every course in these different programmes.

Several studies have commented on the fact that attendance may also be linked to other forms of motivation and commitment (e.g. Gump 2005; Marburger 2001). Attendance has, for instance, been described as a "broad measure of active engagement" (Gracia and Jenkins 2002) and of "commitment to PBL" (van Berkel and Schmidt 2000). Yet, other scholars have argued that the effects of (non-)attendance appear to be independent of factors such as students' ability. For instance, based on a study of attendance and study results of students in undergraduate economics classes at three universities, Romer (1993) discerned a statistically significant relation between attendance and results, even when controlling for other possible 
factors - including motivation, which he took into account by also only looking at students who completed all course work (cf. Durden and Ellis 2003). A similar point is made by Woodfield et al. (2006), who argue that the effects of (non-)attendance appear to be independent of factors such as students' ability. Finally, Credé et al. (2010) look at different models which may explain this relationship in their meta-study on the influence of attendance on study results. The authors argue that the "unique effects model", in which there is a strong relationship between attendance and grades with only a weak role for student characteristics, offers the best explanatory value and that "the benefits of better attendance in college classes are likely to be substantial." (p. 286).

Studying the impact of attendance is important because it can inform policy decisions regarding rules, regulations and curriculum design in higher education. One of the key points of debate concerns the question whether or not higher education institutions should intervene on matters related to attendance, for instance by setting minimum attendance requirements. Studies report that students do not object to interventions; they actually perceive them as a sign that university cares about them (Bevitt et al. 2010; Bowen et al. 2005). Yet, scholars are not always keen on such measures. St. Clair (1999) has argued against compulsory attendance. She believes that existing studies do not provide enough justification for such policies, also because they would ignore other factors that influence study success. Instead, she argues that students should want to attend, instead of being forced to. This way they feel in control and will be better motivated. St. Clair's emphasis on enjoying learning and feeling responsible certainly would be more in line with the basic premises of active learning environments such as PBL.

\section{Problem-based learning in the BA ES}

The aforementioned challenges and issues have also been at the centre of debate in Dutch higher education, including in relation to Maastricht University's BA ES, the focus of the current study. This 3-year, interdisciplinary undergraduate programme focuses on Europe in its broadest sense, including European integration, cultural and religious fault lines and European history. Courses are jointly developed and taught by an international staff team, representing several disciplinary backgrounds. Due to the fact that the programme is fully taught in English, it attracts students from all over Europe and even from outside Europe.

As Jansen et al. (2017) show, such a diverse and international student body creates additional challenges as far as academic and social integration is concerned. In order to address such issues, the BA ES introduced a "Matching" intake procedure, an enhanced induction for new students and a revised mentor programme from 2011 onwards (Bijsmans and Harbers 2014). In addition, just like other programmes at Maastricht University, from its inception in 2002 the BA ES curriculum has been shaped in accordance with the principles of PBL, with learning usually taking place in small groups of maximum 15 students (Maurer 2015; Maurer and Neuhold 2014).

Moust et al. (2005) argue that throughout the years, PBL has seen an "erosion" of its original premises, including decreasing student engagement with the pre-discussion, increasing group size and course coordinators that prescribe literature. One related issue concerns students' attendance and participation, which are considered to be of key importance for a fruitful PBL learning community (e.g. Loyens et al. 2012, p. 419). In the words of Maurer (2015, p. 372), "PBL builds upon collaborative learning by assuming that deliberation and discussion advance knowledge and understanding". 
Also within the BA ES' home Faculty of Arts and Social Sciences (FASoS), there have been several discussions on the role of attendance. The BA ES has always employed minimum attendance requirements, but questions have been raised about the resulting administrative requirements and about the suitability of attendance rules in a PBL environment that stresses self-responsibility. Our research was partially inspired by these discussions, which often were opinion-driven, rather than evidence-based. In addition, while educational scientists have done research into the matter, there is hardly any research on the impact of (non-)attendance in active learning environments, in general, and PBL, in particular (Bevitt et al. 2010, p. 8; Eisen et al. 2015, p. 814). We seek to contribute to this debate by looking at the impact of attendance in PBL in the BA ES and purposefully broaden the definition of study success by looking at three indicators, namely passing the BSA threshold, obtained ECTS (European Credit Transfer System) and GPA.

\section{Research design}

While most studies are small in terms of their design (for an exception, see Newman-Ford et al. 2008), our research is aimed at assessing the importance of (non-)attendance on the study success of first-year BA ES students of three cohorts (2012/2013, 2013/2014, 2014/2015). The main reason for focussing on these cohorts is that the students in question have all had to complete the aforementioned Matching procedure, which is aimed at helping prospective students make the right study choice. Among other things, this procedure stimulates reflection about motivation to study European Studies. Data have been anonymised to avoid potential privacy issues.

Study success in our research takes two forms. First and foremost, it concerns retention. Consequently, the first question addressed in this paper asks whether we can discern differences in course attendance between students who passed the BSA threshold-42 or more ECTS - required to continue their studies and those who did not. We also look at the effect of attendance on the total number of ECTS obtained at the end of the first year. Second, study success can be defined in terms of grades. Therefore, does course attendance effect students' grade point average (GPA)? Not only will we address this issue by comparing end-of-the-year results, but we will also discuss whether attendance in one period is more important than in another period.

In the analyses presented below, we look at three sub-groups of students. The first group consists of 650 students (out of the 1059 students originally enrolled at the start of the three academic years) who attended all courses throughout the first year. ${ }^{2}$ This group of students consists of slightly more women (54\%) than men (46\%) and is highly international, though German students by far comprise the most substantial group (44\%, 20\% Dutch, $8 \%$ Belgians, $7 \%$ Italian, $6 \%$ UK, and $15 \%$ other countries; comparable figures apply to country of preeducation). The average age is 19.6 years (with a standard deviation of 1.8 years; minimum is 16 and maximum is 41 years). Descriptive statistics per cohort are provided in Tables 5, 6, and 7 in the Appendix.

We differentiate between (1) the group of 650 students who attended all courses during their first year, (2) students who additionally passed the BSA threshold $(N=548)$ and (3) students

\footnotetext{
${ }^{2}$ The drop-out rate lies around $25 \%$ which can explain 265 out of a total of 1059 students dropping out. This means that 144 students were not enrolled in one or more courses offered in the first year.
} 
Table 1 Sub-groups of students included in the analyses

Total enrolment

who also attended the minimum number of required meetings at the end of the first year $(N=$ 326) (Table 1). ${ }^{3}$ The descriptive statistics remain by and large the same for these groups of students. The rationale for narrowing down the sample of students is that we may expect that students who pass the BSA threshold, and those who do not only pass this threshold but who also attend the minimum number of required meetings, tend to be the more committed students. When attendance matters for the most committed students, then it is very likely that attendance matters for all students (cf. Romer 1993).

Table 8 in the Appendix presents the courses offered in the first year of the BA ES. Some skills courses are not graded in accordance with the 1-10 Dutch numerical scale, ${ }^{4}$ but with a fail, pass or excellent. Attendance and ECTS for these courses are included in our attendance and ECTS measures, but these courses are excluded when we calculate GPA.

Our main independent variable of interest is attendance. Table 9 in the Appendix displays the minimum and maximum number of tutorials students need to or can attend during a period, or at the end of each period including the end of the first year (period 5). A student who has met the minimum attendance requirements at the end of the first year has attended 53 to 60 tutorials whereas a student who did not miss any meetings attended no less than 74 to 79 tutorials. Since the number of total and required tutorials as well as curriculum changes varies per cohort ${ }^{5}$, we express attendance as a ratio of total meetings (Table 9 in the Appendix).

Our main dependent variable is study success. Specifically, we look at three forms of study success, namely passing the BSA threshold, obtained ECTS and GPA. Meeting the BSA threshold is operationalised as a dummy variable ( $1=$ having earned 42 or more ECTS). Obtained ECTS is operationalised as a ratio of total ECTS (60 credits). GPA is an average of obtained grades (on a scale from 1 to 10) weighted by the number of ECTS for the respective courses. In the statistical models presented below, we include several control variables: gender $(0=$ men; $1=$ women), age (number of years), nationality (country) and pre-education (country).

\section{Impact of attendance on receiving a positive BSA}

The first question we take up is whether attending more tutorials increases the likelihood of passing the BSA threshold. Table 2 presents the results of a logit regression model exploring the effects of the total number of attended tutorials at the end of the first year on meeting the BSA requirement $(1=$ yes; $0=$ no). The model controls for gender, age, nationality and country of pre-education.

\footnotetext{
${ }^{3}$ The total numbers of students may alter slightly depending on missing data on the measurement of study success.

${ }^{4}$ Where a 10 is the highest possible grade and a 6 is the minimum passing grade.

${ }^{5}$ The course Fault Lines was a lecture based course in 2012-2013, with PBL sessions being (re-)introduced in 2013-2014. This is also partly the reason why the number of required and total meetings increased respectively from 53 to 60 and from 74 to 79 for cohorts 2013-2014 and 2014-2015.
} 
Table 2 Effect of attendance on meeting the binding study advice of 42 ECTS

\begin{tabular}{|c|c|c|c|c|c|c|}
\hline & \multicolumn{3}{|l|}{ ALL } & \multicolumn{3}{|l|}{ MIN } \\
\hline & $\beta$ & s.e. & sig. & $\beta$ & s.e. & sig. \\
\hline Cum. attendance end year 1 & 15.781 & 1.684 & $* *$ & 15.122 & 4.032 & $* *$ \\
\hline Gender & -0.178 & 0.284 & & -0.652 & 0.463 & \\
\hline Age & -0.043 & 0.075 & & -0.038 & 0.124 & \\
\hline Nationality & 0.122 & 0.105 & & 0.078 & 0.187 & \\
\hline Pre-education & -0.111 & 0.102 & & -0.204 & 0.184 & \\
\hline Constant & -10.495 & 1.924 & $* *$ & -9.253 & 4.513 & $*$ \\
\hline$N$ & 650 & & & 352 & & \\
\hline Log likelihood & -184 & & & -82 & & \\
\hline McFadden $R^{2}$ (adj.) & 0.348 & & & 0.111 & & \\
\hline
\end{tabular}

Notes: Shown are the results of a logit regression model estimating the probability that a student meets the binding study advice. MIN stands for students who attended the required number of tutorials to pass for attendance

$* p<0.05 ; * * p<0.01$

Attendance has a positive and statistically significant effect on meeting the BSA requirement. Substantive effects cannot be directly interpreted from the regression results presented in Table 2 . Therefore, we have calculated the effects of attendance for a German woman of 20 years who received her pre-education in Germany. This "type" of student was chosen because it is the most common student of the first year (see Tables 5, 6, and 7 in the Appendix). In addition, annual study progress data from our student advisors shows that they are the best-performing students and often are present during almost all meetings. In other words, we may expect the least impact of attendance for this type of student (cf. Woodfield et al. 2006). Students who attended all meetings (100\%, 74 meetings for cohort 2012-2013 or 79 meetings for cohorts 2013-2014 and 2014-2015) have a $99 \%$ probability of meeting the BSA of 42 or more ECTS whereas this probability is $46 \%$ for students who attended the minimum number of meetings ( $72 \%$ of the total number of meetings). We get very similar results when we restrict the analysis to students who have at least attended the required number of meetings in order to pass for attendance (MIN).

\section{Impact of attendance on obtained ECTS}

We also explore the effect of attendance on the total ECTS obtained at the end of the first year. Some descriptive statistics (Table 3) are already quite revealing. Students who have earned at least 55 of the maximum of 60 ECTS have attended on average $92 \%$ of the total number of tutorials. This is statistically significantly more than students who obtained less than 55 ECTS. All the differences in means reported in Table 3 are statistically significant $(p<0.05)$ which strongly suggests that students who attend more tutorials also tend to acquire more ECTS.

In Table 4, we present the results of three ordinary least square regression models which allow us to explore the effect of attendance on the number of earned ECTS at the end of the first year for three different groups of students: all students (ALL; $N=650$ ), students who met the BSA requirement (BSA; $N=548$ ) and students who met the BSA requirement and who also attended the minimum number of required meetings at the end of the first year (BSA + MIN; $N=326$ ).

The beta coefficient of our main independent variable of interest, the percentage of attended meetings of the total number of meetings at the end of the first year, is positive and statistically 
Table 3 Average attendance in percentage of total meetings per ECTS group

\begin{tabular}{llrrrr}
\hline ECTS & Mean & SD & $N$ & Min & Max \\
\hline$<42$ & 70.5 & 19.1 & 103 & 1.3 & 94.9 \\
$42-48$ & 82.8 & 7.4 & 88 & 56.8 & 96.2 \\
$49-54$ & 86.4 & 6.5 & 88 & 68.9 & 98.7 \\
$55-60$ & 91.6 & 5.3 & 671 & 74.3 & 100.0 \\
Total & 86.4 & 12.0 & 650 & 1.3 & 100.0 \\
\hline
\end{tabular}

Notes: all differences in means are statistically significantly different at $p<0.05$ (ANOVA, $F=143.99, p<0.001$ )

significant for all three groups of students. Yet, the size of the beta coefficient, and hence the impact of attendance, is declining. This is clearly shown when we look at the substantive effects. Each $1 \%$ additional percentage attendance translates into $1.5 \%$ extra obtained ECTS when we look at the whole pool of students who have attended all courses throughout the year. The difference in average percent attended meetings between the group of students who obtained 42-48 ECTS (82.8\%) and those who acquired 55-60 ECTS (91.6\%) is $8.8 \%$ (Table 3). This difference translates into $13.2 \%$ extra earned ECTS $(8.8 \% \times 1.5 \%)$, that is 7.9 ECTS $(13.2 \%$ of 60 ECTS).

Table 4 Effect of attendance on obtained ECTS at the end of the first year

\begin{tabular}{|c|c|c|c|c|c|c|c|c|c|}
\hline & \multicolumn{3}{|l|}{ ALL } & \multicolumn{3}{|l|}{ BSA } & \multicolumn{3}{|c|}{$\mathrm{BSA}+\mathrm{MIN}$} \\
\hline & $\beta$ & s.e. & sig. & $\beta$ & s.e. & sig. & $\beta$ & s.e. & sig. \\
\hline Cum. attendance end year 1 & 1.468 & 0.053 & $* * *$ & 0.675 & 0.055 & $* * *$ & 0.601 & 0.094 & $* * *$ \\
\hline Gender $($ male $=0)$ & 0.014 & 0.013 & & 0.009 & 0.007 & & 0.012 & 0.010 & \\
\hline Age & -0.003 & 0.003 & & -0.001 & 0.002 & & -0.001 & 0.003 & \\
\hline \multicolumn{10}{|c|}{ Nationality (Dutch = base category) } \\
\hline Belgium & 0.105 & 0.041 & $* * *$ & 0.046 & 0.025 & $*$ & 0.028 & 0.032 & \\
\hline Germany & 0.069 & 0.035 & $* *$ & 0.062 & 0.021 & $* *$ & 0.056 & 0.030 & $*$ \\
\hline Italy & 0.110 & 0.047 & $* *$ & 0.031 & 0.028 & & 0.029 & 0.033 & \\
\hline UK & 0.0223 & 0.038 & & 0.015 & 0.023 & & 0.034 & 0.030 & \\
\hline Other & 0.051 & 0.031 & $*$ & 0.017 & 0.019 & & 0.092 & 0.028 & \\
\hline \multicolumn{10}{|c|}{ Pre-education (Dutch = base category) } \\
\hline Belgium & -0.061 & 0.039 & & -0.019 & 0.024 & & -0.014 & 0.031 & \\
\hline Germany & -0.041 & 0.037 & & -0.046 & 0.023 & $* *$ & -0.050 & 0.032 & \\
\hline Italy & -0.076 & 0.051 & & -0.023 & 0.031 & & -0.032 & 0.037 & \\
\hline UK & -0.045 & 0.039 & & -0.025 & 0.024 & & -0.061 & 0.031 & $*$ \\
\hline Other & -0.038 & 0.031 & & -0.017 & 0.019 & & -0.026 & 0.028 & \\
\hline Constant & -0.384 & 0.082 & $* * *$ & 0.322 & 0.062 & $* * *$ & 0.417 & 0.112 & $* * *$ \\
\hline$N$ & 650 & & & 548 & & & 326 & & \\
\hline Root MSE & 0.157 & & & 0.084 & & & 0.085 & & \\
\hline Adj. $R^{2}$ & 0.566 & & & 0.250 & & & 0.130 & & \\
\hline
\end{tabular}

Notes: Shown are the results (beta coefficients and their standard errors) of an ordinary least regression model on the number of ECTS obtained at the end of the first year. The model is run for all students (ALL), for students who met the BSA requirement (BSA) and for students who met the BSA requirement and attended the minimum number of required meetings at the end of the first year $(\mathrm{BSA}+\mathrm{MIN})$

$* p<0.10 ; * * p<0.05 ; * * * p<0.01$ 
When we confine the analysis to students who have obtained their BSA or who have their BSA and attended the minimum required meetings for all courses (BSA + MIN) then attendance still matters. For these students, each $1 \%$ additional percentage attendance results in 0.6 to $0.7 \%$ extra obtained ECTS. The minimum required percentage of meetings that a student needs to have attended at the end of the academic year is 72 to $76 \%$ (Table 8). The difference in earned ECTS with a student who has attended all meetings $(100 \%)$ is 14.4 to 16.8 ECTS (i.e. $24-28 \% \times 0.6 \%$ ).

\section{Impact of attendance on GPA}

The previous analyses on the impact of attendance on receiving a positive BSA and on earned ECTS focused on study success at the end of the academic year. A focus on GPA allows us to assess the impact of attendance on study success at multiple time points throughout the academic year. In the BA ES, courses are taught in five periods whereby the last week is mostly kept free from teaching because of examinations. ${ }^{6}$ Another major advantage of looking at the impact of attendance per period is that we can control for GPA obtained in the previous period. The GPA of the previous period serves as an indicator for commitment to the programme, among other things such as intelligence. Therefore, we are more closely assessing the impact of attendance rather than something such as broader engagement.

Below, we present the results of multilevel mixed regression models which, in addition to cumulative GPA of the previous period, include dummies for each period and cumulative percentage attendance and their interactions as well as several control variables (gender, age, nationality, country of pre-education). The models enable us to assess the impact of attendance on cumulative GPA per period. Periodic GPA is measured for five periods for each student, and students are clustered in three cohorts. We include random effects for each student and three cohorts to control for dependencies arising from clustering. The models also include an autocorrelation coefficient (rho) for periods. The full regression model results are presented in Table 10 in the Appendix. Figure 1 displays the impact of attendance for 590 students who attended all courses in the first year. Figure 2 displays the impact of attendance for 322 students who attended the minimum required of meetings for all courses and who passed the BSA threshold of 42 out of 60 ECTS. Estimates for period 1 cannot be displayed because these observations are dropped from the model while GPA for the previous period is absent.

Three observations are especially noteworthy. First, attendance is statistically significant across the periods and across the groups of students. This result strongly indicates that attendance matters and positively impacts GPA beyond anything else that is captured by the GPA of the previous period. Attendance matters even for the most engaged and committed students who have attended at least the required number of meetings for all courses offered in the first year and who are well-performing because they received a positive BSA (Fig. 2). Although the magnitude of the effect is smaller than for the whole group of students who attended in all courses (Fig. 1), the effect is statistically significant and adds to the effect of GPA obtained in the previous period. Depending on the period and on the group of students,

$\overline{{ }^{6} \text { Periods 1, 2, } 4 \text { and } 5 \text { last } 8 \text { weeks }}$ and period 3 lasts 4 weeks. 


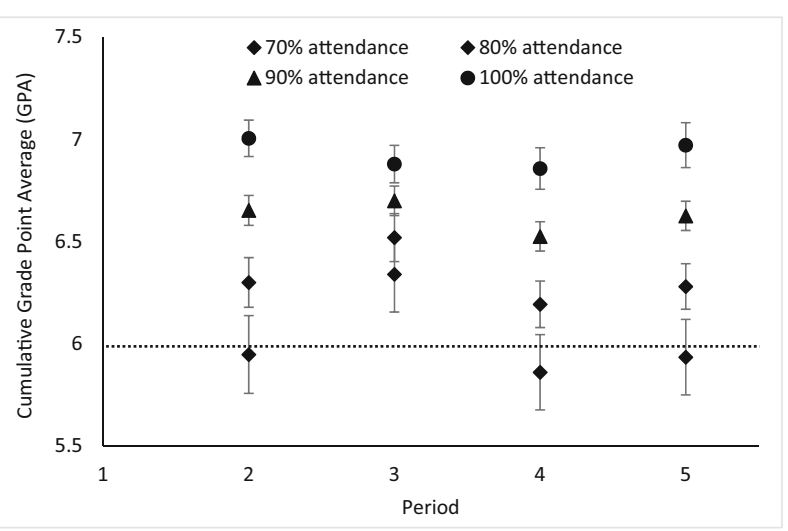

Fig. 1 Effect of attendance on the cumulative grade point average per period. Notes: Shown are estimated cumulative GPA and 95\% confidence intervals. The dashed line indicates the passing grade for a course (6.0). The estimates are based on a multilevel mixed linear regression model whereby 590 students (who attended all courses in the first year) are clustered in three cohorts and which includes an autocorrelation coefficient (rho) to control for over-time (cross-period) dependencies (full model results are shown in Table 10 in the Appendix)

the magnitude of the effect of attendance varies. The difference in GPA at the end of period 5 between a student who attended all meetings (100\%) and a student who attended the minimum required number of meetings ( $70 \%$, Table 9 in the Appendix) is 1.04 for the whole population of students who attended in all courses (Fig. 1) and 0.77 for the group of students who attended at least the required number of meetings and who obtained a positive BSA (Fig. 2).

A second interesting result in Fig. 1 is that the impact of attendance in period 3 is smaller than for periods 2, 4 and 5. The difference in cumulative GPA between a student who attended $70 \%$ of the meetings compared to a student who attended $100 \%$ is 0.54 for period 3 , but about 1.0 for the other three periods (respectively 1.06, 1.0 and 1.04 for periods 2, 4 and 5). This result may be explained by the shorter time span of the module which is 4 instead of 8 weeks.

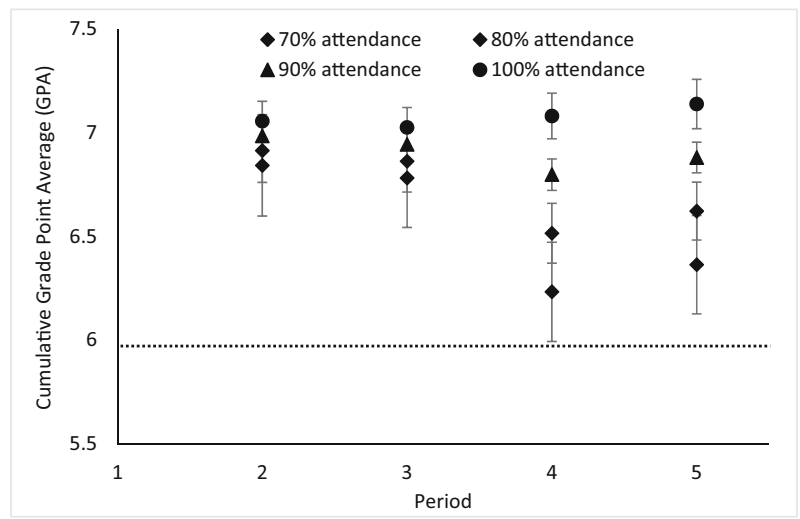

Fig. 2 Effect of attendance on the cumulative grade point average per period. Notes: Shown are estimated cumulative GPA and 95\% confidence intervals. The dashed line indicates the passing grade for a course (6.0). The estimates are based on a multilevel mixed linear regression model whereby 322 students (who attended the minimum required of meetings and who obtained the BSA threshold of 42 out of 60 ECTS) are clustered in three cohorts and which includes an autocorrelation coefficient (rho) to control for over-time (cross-period) dependencies (full model results are shown in Table 10 in the Appendix) 
A third remarkable observation in Fig. 2 is that the impact of attendance is much smaller for periods 2 and 3 when compared to periods 4 and 5. In periods 2 and 3, the difference in cumulative GPA between a student who attended $70 \%$ of the meetings and a student who attended $100 \%$ is 0.21 and 0.24 , but it is 0.85 and 0.77 for periods 4 and 5 . This result suggests that attendance matters also for the highly motivated student and especially so in the longer run. The 95\% confidence intervals in Fig. 2 tend to be considerably larger for the estimates for 70 and $80 \%$ attendance and that is because the highly motivated students tend to attend most meetings. Average cumulative attendance is $93 \%$ with a standard deviation of 5.7\%. Nevertheless, even though practically all these students attend most meetings, the difference in cumulative GPA between a student who attended $90 \%$ of the meetings compared to a student who attended $100 \%$ is 0.28 for period 4 and 0.26 period 5 , and these differences are statistically significant. Thus, our overall conclusion is that attendance matters for study success in a PBL environment, also for the diligent and well-performing student.

\section{Discussion and conclusions}

We started our study by asking whether and to what extent attendance matters for study success in a PBL teaching and learning environment. The findings presented above suggest that attendance has a clear additive impact beyond "active engagement" (Gracia and Jenkins 2002) or "commitment to PBL" (van Berkel and Schmidt 2000). Readers may still raise the (valid) question of whether all of this does not generally depend on the nature of PBL or on students' overall commitment, or whether certain rules create a certain behaviour. In addition, since the bestperforming students also attend more meetings, the results may be due to a certain level of endogeneity. Yet, our data enable us us to look into this by differentiating within the group of students. We find an effect of attendance for different measures of first-year study success in the BA ES (BSA, ECTS, GPA) and at various points of time (per period and end of the year). Even among the committed students, those who met the minimum attendance requirements in all courses, we see that higher attendance has a substantial impact on the amount of ECTS obtained and the end-of-year GPA. Note that these results are found when we control for severable other factors such as gender, age, nationality, pre-education and GPA of the previous period.

All three cohorts studied underwent a Matching procedure, which forces prospective students to reflect on their study choice before the start of the studies, which results in a base line commitment. Attendance should also matter, because the committed student needs to be nourished and confirmed in her committed behaviour or otherwise she will be disillusioned early on. That is, we think that it is through an "ethos of attendance" (Trotter and Roberts 2006, p. 382; cf. Rau and Durand 2000) that attendance matters and is particularly important in a PBL learning environment. Therefore, we think it is safe to conclude that attendance matters for study success, also for the committed, participating and well-prepared student. As such, we agree with Newman-Ford et al. (2008, p. 713) that "the inescapable conclusion is that attendance is a direct determinant of academic performance and attainment".

This brings us back to the policy question that served as one of the starting points of our research, namely whether or not to stick to the minimum attendance requirements in the BA $\mathrm{ES}^{7}$ One of the main arguments underlying the discussions about attendance rules at FASoS is

\footnotetext{
${ }_{7}$ Our data also allows us to look at course level, something which can be particularly useful for both course development and curriculum design.
} 
that it is deemed crucial for effective student performance in a programme based on PBL. Our results indicate that attendance matters more for later periods in the first year. This may be due to decreasing engagement (Brahm et al. 2017; Korhonen et al. 2017). These results may serve as an argument to have a minimum attendance policy throughout the first year.

As such, our data underline the importance of attendance. The importance of integrating first-year students into academia may be reason enough to apply minimum attendance requirements for first-year courses. ${ }^{8}$ In the words of Bevitt et al. (2010, p. 12):

A strong steer at the start of a university career may help to counter stereotypical assumptions about attendance and help to encourage good study and attendance habits from the start. A progressively lighter touch may then be used in subsequent years of study as the students' autonomy increases.

In fact, Trotter and Roberts (2006) present evidence that shows that the best retention rates are achieved by universities where attendance is required and is strictly monitored.

Yet, one could imagine several other policy responses beyond minimum attendance requirements that might actually fit better with the philosophy of PBL. For instance, Rodgers (2002) experimented with an incentive scheme. While attendance did increase, it did not lead to better performance (cf. Eisen et al. 2015, p. 815). Another option is discussed by Moore et al. (2003; cf. Credé et al. 2010, pp. 286-287), who also found that attending class has an influence on results. They showed these findings to students, which resulted in higher class attendance. However, the authors also note that such efforts will probably not have an influence on students who are less concerned about their education.

As was discussed earlier, there are other factors that influence study success, ranging from learning environment to personal factors. Even when we cannot completely rule out the influence of other factors, the findings presented here suggest a noticeable effect of attendance on study success. Hence, it certainly is worth emphasising the importance of attendance. As Gump (2005, p. 21) explains "attendance should be one of the easiest variable for students to control. Students who wish to succeed academically should attend class, and instructors should likewise encourage class attendance". Yet, in PBL in particular, it is not just attendance that should matter for building learning communities, but also preparation and participation (cf. Remedios et al. 2008). Since our data is administrative in nature, we cannot reflect on these and other factors (e.g. motivation and self-efficacy). In addition, to colour-in the quantitative data, it would also be interesting to ask students for their view on the importance of attendance. These are issues that we plan to look at in our future research.

Acknowledgments We would like to thank the participants in the 2nd Conference on Teaching and Learning Politics, International Relations and European Studies (Brussels, 9-10 June 2016), the participants in the 46th Annual UACES Conference (London, 5-7 September 2016), and faculty colleagues in the "Politics and Culture in Europe" seminar for feedback on earlier versions of this manuscript.

We would also like to thank Maastricht University's Faculty of Arts and Social Sciences for administrative and financial support for this research and, in particular, Maike Schmeitz for her assistance at the start of the project.

We thank both anonymous reviewers for their thorough and constructive feedback.

\footnotetext{
${ }^{8}$ For suggestions for minimum attendance thresholds or tipping points for intervention, see Bevitt et al. 2010; Jansen and Suhre 2010.
} 


\section{Appendix}

Table 5 Gender

\begin{tabular}{|c|c|c|c|c|c|}
\hline \multirow[t]{2}{*}{ Cohort } & \multicolumn{2}{|c|}{ Male } & \multicolumn{2}{|c|}{ Female } & \multirow{2}{*}{$\begin{array}{l}\text { Total } \\
N\end{array}$} \\
\hline & $N$ & $\%$ & $N$ & $\%$ & \\
\hline $2012-2013$ & 90 & 45.9 & 106 & 54.1 & 196 \\
\hline 2013-2014 & 84 & 46.2 & 98 & 53.8 & 182 \\
\hline 2014-2015 & 125 & 45.6 & 149 & 54.4 & 274 \\
\hline Total & 299 & 45.9 & 353 & 54.1 & 652 \\
\hline
\end{tabular}

Table 6 Age

\begin{tabular}{lllll}
\hline Cohort & Mean & SD & Min & Max \\
\hline $2012-2013$ & 19.7 & 2.43 & 17 & 41 \\
$2013-2014$ & 19.6 & 1.53 & 16 & 28 \\
$2014-2015$ & 19.6 & 1.53 & 18 & 27 \\
Total & 19.6 & 1.84 & 16 & 41 \\
\hline
\end{tabular}

Table 7 Nationality and country of pre-education

\begin{tabular}{lrrrr} 
& \multicolumn{2}{c}{ Nationality } & & \multicolumn{2}{l}{ Pre-education } \\
\cline { 2 - 3 } \cline { 5 - 5 } & \multicolumn{1}{c}{$N$} & $\%$ & & $N$ \\
\hline Netherlands & 132 & 20.2 & 104 & 16.0 \\
Belgium & 54 & 8.3 & 73 & 11.2 \\
German & 286 & 43.9 & 259 & 39.7 \\
UK & 41 & 6.3 & 44 & 6.7 \\
Italy & 44 & 6.7 & 134 & 5.8 \\
Other & 95 & 14.6 & 652 & 20.6 \\
Total & 652 & 100.0 & & 100.0 \\
\hline
\end{tabular}


Table 8 Course descriptions of the first-year courses of Maastricht University's BA ES

\begin{tabular}{|c|c|c|c|c|}
\hline Course & Title & Period & Grade & ECTS \\
\hline EUS1000 & The Idea of Europe & 1 & $1-10$ & 5 \\
\hline EUS1001 & Introduction to Academic Research and Writing & 1 & $1-10$ & 5 \\
\hline EUS1500 & Academic English Writing Skills & 1 & $1-10$ & 1.5 \\
\hline EUS1507 & English Language Diagnostic Test & 1 & $\mathrm{P}$ & 0.5 \\
\hline EUS1002 & Bloody Diversity & 2 & $1-10$ & 9 \\
\hline EUS1501 & Academic English Writing and Presentation Skills & 2 & $1-10$ & 2 \\
\hline EUS1007 & Europe and Global Politics Since World War II & 3 & $1-10$ & 4.5 \\
\hline EUS1505 & What is Good Science? & 3 & $\mathrm{~F} / \mathrm{P} / \mathrm{E}$ & 2 \\
\hline EUS1003 & Fault Lines & $3-4$ & $1-10$ & 5 \\
\hline EUS1005 & An Economist Point of View & 4 & $1-10$ & 6 \\
\hline EUS1008 & Micro/Macro Economics & 4 & $1-10$ & 6 \\
\hline EUS1006 & EU Politics: Theories, Institutions and Challenges & 5 & $1-10$ & 9 \\
\hline EUS1504 & Analysing Research Designs & 5 & $\mathrm{~F} / \mathrm{P} / \mathrm{E}$ & 4.5 \\
\hline \multirow[t]{2}{*}{ EUS1508 } & Mentor Programme & $1-5$ & - & 0 \\
\hline & & & Total & 60 \\
\hline
\end{tabular}

Notes: EUS15008 is not included for attendance, GPA and ECTS. EUS1500 is not included for attendance because the course has no small scale tutorials. EUS1504, EUS1505 and EUS1507 are not included for GPA

$F$ fail, $P$ pass, $E$ excellent

Table 9 Number of tutorials/meetings and ECTS per cohort and per period

\begin{tabular}{|c|c|c|c|c|c|c|c|c|c|}
\hline \multirow[t]{2}{*}{ Cohort } & \multirow[t]{2}{*}{ Period } & \multicolumn{6}{|c|}{ Tutorials/meetings } & \multicolumn{2}{|c|}{ ECTS } \\
\hline & & Min & Tot & $\%$ & Cum min & Tot cum & $\%$ & $N$ & $\mathrm{~N}$ cum \\
\hline \multirow[t]{5}{*}{ 2012-2013 } & 1 & 10 & 13 & 0.77 & 10 & 13 & 0.77 & 12 & 12 \\
\hline & 2 & 14 & 19 & 0.74 & 24 & 32 & 0.75 & 11 & 23 \\
\hline & 3 & 7 & 10 & 0.70 & 31 & 42 & 0.74 & 6.5 & 29.5 \\
\hline & 4 & 9 & 15 & 0.60 & 40 & 57 & 0.70 & 17 & 46.5 \\
\hline & 5 & 13 & 17 & 0.76 & 53 & 74 & 0.72 & 13.5 & 60 \\
\hline \multirow[t]{5}{*}{ 2013-2014 } & 1 & 11 & 13 & 0.85 & 11 & 13 & 0.85 & 12 & 12 \\
\hline & 2 & 14 & 19 & 0.74 & 25 & 32 & 0.78 & 11 & 23 \\
\hline & 3 & 8 & 10 & 0.80 & 33 & 42 & 0.79 & 6.5 & 29.5 \\
\hline & 4 & 13 & 20 & 0.65 & 46 & 62 & 0.74 & 17 & 46.5 \\
\hline & 5 & 14 & 17 & 0.82 & 60 & 79 & 0.76 & 13.5 & 60 \\
\hline \multirow[t]{5}{*}{$2014-2015$} & 1 & 10 & 13 & 0.77 & 10 & 13 & 0.77 & 12 & 12 \\
\hline & 2 & 14 & 19 & 0.74 & 24 & 32 & 0.75 & 11 & 23 \\
\hline & 3 & 7 & 10 & 0.70 & 31 & 42 & 0.74 & 6.5 & 29.5 \\
\hline & 4 & 15 & 20 & 0.75 & 46 & 62 & 0.74 & 17 & 46.5 \\
\hline & 5 & 13 & 17 & 0.76 & 59 & 79 & 0.75 & 13.5 & 60 \\
\hline
\end{tabular}


Table 10 The impact of attendance on the cumulative Grade Point Average (GPA)

\begin{tabular}{|c|c|c|c|c|c|c|}
\hline & \multicolumn{3}{|l|}{ ALL } & \multicolumn{3}{|c|}{$\mathrm{MIN}+\mathrm{BSA}$} \\
\hline & $b$ & s.e. & sig. & $b$ & s.e. & sig. \\
\hline Lagged cumulative GPA & 0.72 & 0.01 & $*$ & 0.71 & 0.02 & $*$ \\
\hline Cumulative attendance (\%) & 3.53 & 0.40 & $*$ & 0.71 & 0.50 & \\
\hline Dummy period 3 & 1.60 & 0.41 & $*$ & -0.13 & 0.57 & \\
\hline Dummy period 4 & 0.05 & 0.45 & & -2.09 & 0.61 & $*$ \\
\hline Dummy period 5 & 0.03 & 0.47 & & -1.79 & 0.62 & * \\
\hline Att. $(\%) *$ Dum. period 3 & -1.73 & 0.44 & $*$ & 0.10 & 0.61 & \\
\hline Att. $(\%)^{*}$ Dum. period 4 & -0.20 & 0.49 & & 2.11 & 0.66 & $*$ \\
\hline Att. $(\%)^{*}$ Dum. period 5 & -0.07 & 0.51 & & 1.87 & 0.67 & * \\
\hline Gender $($ male $=0)$ & 0.00 & 0.04 & & 0.03 & 0.04 & \\
\hline Age & 0.00 & 0.01 & & 0.00 & 0.01 & \\
\hline \multicolumn{7}{|c|}{ Nationality (Dutch = base category) } \\
\hline Belgium & -0.05 & 0.12 & & -0.06 & 0.11 & \\
\hline German & 0.01 & 0.10 & & 0.07 & 0.11 & \\
\hline UK & -0.01 & 0.11 & & 0.06 & 0.11 & \\
\hline Italy & 0.21 & 0.14 & & 0.06 & 0.12 & \\
\hline Other & -0.11 & 0.09 & & -0.12 & 0.10 & \\
\hline \multicolumn{7}{|c|}{ Country of pre-education (Dutch $=$ base category) } \\
\hline Belgium & 0.10 & 0.12 & & 0.10 & 0.11 & \\
\hline German & 0.05 & 0.11 & & 0.00 & 0.11 & \\
\hline UK & 0.01 & 0.11 & & -0.04 & 0.11 & \\
\hline Italy & -0.17 & 0.15 & & 0.01 & 0.13 & \\
\hline Other & 0.03 & 0.09 & & 0.05 & 0.10 & \\
\hline Constant & -1.42 & 0.40 & $*$ & 1.40 & 0.53 & * \\
\hline rho & 0.12 & 0.04 & & 0.06 & 0.07 & \\
\hline Log likelihood & -1954 & & & -815 & & \\
\hline Variance cohort & 0.00 & 0.00 & & 0.00 & 0.00 & \\
\hline Variance student & 0.09 & 0.02 & & 0.04 & 0.02 & \\
\hline Variance residual & 0.28 & 0.02 & & 0.18 & 0.01 & \\
\hline
\end{tabular}

Notes: Shown are the results of a multilevel mixed linear regression model whereby students are clustered in three cohorts and which includes an autocorrelation coefficient (rho) to control for over-time (cross-period) dependencies. The analysis for ALL includes 2254 observations for 590 students who attended in all courses of year 1. The analysis for MIN + BSA includes 1265 observations for 322 students who attended the minimum required meetings of all course of year 1 and who surpassed the BSA threshold of 42 out of 60 ECTS

$* p<0.01$

Open Access This article is distributed under the terms of the Creative Commons Attribution 4.0 International License (http://creativecommons.org/licenses/by/4.0/), which permits unrestricted use, distribution, and reproduction in any medium, provided you give appropriate credit to the original author(s) and the source, provide a link to the Creative Commons license, and indicate if changes were made.

\section{References}

Bevitt, D., Baldwin, C., \& Calvert, J. (2010). Intervening early: attendance and performance as a trigger for first year support in the biosciences. Bioscience Education, 15(1), 1-14.

Bijsmans, P., \& Harbers, P. (2014). The use of Matching as a study choice aid by Maastricht University's Bachelor in European Studies: facilitating transition to higher education? Journal of Contemporary European Research, 10(4), 456-471.

Bowen, E., Price, T., Lloyd, S., \& Thomas, S. (2005). Improving the quantity and quality of attendance data to enhance student retention. Journal of Further and Higher Education, 29(4), 375-385. 
Brahm, T., Jenert, T., \& Wagner, D. (2017). The crucial first year: a longitudinal study of students' motivational development at a Swiss Business School. Higher Education, 73(3), 459-478.

Briggs, A. R. J., Clark, J., \& Hall, I. (2012). Building bridges: understanding student transition to university. Quality in Higher Education, 18(1), 3-21.

Bruinsma, M., \& Jansen, E. P. W. A. (2009). When will I succeed in my first-year diploma? Survival analysis in Dutch higher education. Higher Education Research and Development, 28(1), 99-114.

Coertjens, L., Brahm, T., Trautwein, C., \& Lindblom-Ylänne, S. (2017). Students' transition into higher education from an international perspective. Higher Education, 73(3), 357-369.

Credé, M., Roch, S. G., \& Kieszczynka, U. M. (2010). Class attendance in college: a meta-analytic review of the relationship of class attendance with grades and student characteristics. Review of Educational Research, $80(2), 272-295$.

Durden, G., \& Ellis, L. (2003). Is class attendance a proxy variable for student motivation in economics classes? An empirical analysis. International Social Science Review, 78(1-2), 42-46.

Eisen, D. B., Schupp, C. W., Isseroff, R. R., Ibrahimi, O. A., Ledo, L., \& Armstrong, A. W. (2015). Does class attendance matter? Results from a second-year medical school dermatology cohort study. International Journal of Dermatology, 54(7), 807-816.

Georg, W. (2009). Individual and institutional factors in the tendency to drop out of higher education: A multilevel analysis using data from the Konstanz Student Survey. Studies in Higher Education, 34(6), $647-661$.

Gracia, L., \& Jenkins, E. (2002). An exploration of student failure on an undergraduate accounting programme of study. Accounting Education, 11(1), 93-107.

Gump, S. E. (2005). The cost of cutting class: attendance as a predictor of success. College Teaching, 53(1), 2126.

Jansen, E. P. W. A., \& Suhre, C. J. M. (2010). The effect of secondary school study skills preparation on first-year university achievement. Educational Studies, 36(5), 569-580.

Jansen, E., Suhre, C., \& André, S. (2017). Transition to an international degree programme. Preparedness, firstyear experiences and success of students of different nationalities. In E. Kyndt, V. Donche, K. Trigwell, \& S. Lindblom-Ylänne (Eds.), Higher education transitions. Theory and research (pp. 47-65). London: Routledge.

Korhonen, V., Inkinen, M., Mattsson, M., \& Toom, A. (2017). Student engagement and the transition from the first to second year in higher education. In E. Kyndt, V. Donche, K. Trigwell, \& S. Lindblom-Ylänne (Eds.), Higher education transitions. Theory and research (pp. 113-134). London: Routledge.

Kyndt, E., Donche, V., Trigwell, K., \& Lindblom-Ylänne, S. (Eds.). (2017). Higher education transitions. Theory and research. London: Routledge.

Leveson, L., McNeil, N., \& Joiner, T. (2013). Persist or withdraw: the importance of external factors in students' departure intentions. Higher Education Research and Development, 32(6), 932-945.

Loyens, S.M.M., Kirschner, P.A., Paas, F. (2012). Problem-based learning. In K.R. Harris, S. Graham, T. Urdan (Eds.), APA educational psychology handbook: Vol. 3. Application to teaching and learning (pp. 403-425). Washington, D.C.: American Psychological Association.

Marburger, D. R. (2001). Absenteeism and undergraduate exam performance. The Journal of Economic Education, 32(2), 99-109.

Maurer, H. (2015). Best practices in problem-based learning. In J. Ishiyama, W. J. Miller, \& E. Simon (Eds.), Handbook on teaching and learning in political science and international relations (pp. 369-383). Cheltenham: Edward Elgar.

Maurer, H., \& Neuhold, C. (2014). Problem-based learning in European studies. In S. Baroncelli, R. Farneti, I. Horga, \& S. Vanhoonacker (Eds.), Teaching and learning the European Union. Traditional and innovative methods (pp. 199-215). Dordrecht: Springer.

Moore, R., Jensen, M., Hatch, J., Duranczyk, I., Staats, S., \& Koch, L. (2003). Showing up: the importance of class attendance for academic success in introductory science courses. The American Biology Teacher, 65(5), 325-329.

Moust, J. H. C., van Berkel, H. J. M., \& Schmidt, H. G. (2005). Signs of erosion: reflections on three decades of problem-based learning at Maastricht University. Higher Education, 50(4), 665-683.

Newman-Ford, L., Fitzgibbon, K., Lloyd, S., \& Thomas, S. (2008). A large-scale investigation into the relationship between attendance and attainment: a study using an innovative, electronic attendance monitoring system. Studies in Higher Education, 33(6), 699-717.

Rau, W., \& Durand, A. (2000). The academic ethic and college grades. Does hard work help students to "make the grade"? Sociology of Education, 73(1), 19-38.

Remedios, L., Clarke, D., \& Hawthorne, L. (2008). The silent participant in small group collaborative learning contexts. Active Learning in Higher Education, 9(3), 201-216. 
Rodgers, J. R. (2002). Encouraging tutorial attendance at university did not improve performance. Australian Economic Papers, 41(3), 255-266.

Romer, D. (1993). Do students go to class? Should they? Journal of Economic Perspectives, 7(3), 167-174.

St. Clair, K. L. (1999). A case against compulsory class attendance policies in higher education. Innovative Higher Education, 23(3), 171-180.

Tinto, V. (1997). Classrooms as communities. Exploring the educational character of student persistence. Journal of Higher Education, 68(6), 599-623.

Tinto, V. (2017). Through the eyes of students. Journal of College Student Retention: Research, Theory and Practice, 19(3), 254-269.

Trautwein, C., \& Bosse, E. (2017). The first year in higher education-critical requirements from the student perspective. Higher Education, 73(3), 371-387.

Trotter, E., \& Roberts, C. A. (2006). Enhancing the early student experience. Higher Education Research and Development, 25(4), 371-386.

van Berkel, H. J. M., \& Schmidt, H. G. (2000). Motivation to commit oneself as a determinant of achievement in problem-based learning. Higher Education, 40(2), 231-242.

Wilcox, P., Winn, S., \& Fyvie-Gauld, M. (2005). 'It was nothing to do with the university, it was just the people': the role of social support in the first-year experience of higher education. Studies in Higher Education, 30(6), 7-7-722.

Woodfield, R., Jessop, D., \& McMillan, L. (2006). Gender differences in undergraduate attendance rates. Studies in Higher Education, 31(1), 1-22.

Zhao, C.-M., \& Kuh, G. D. (2004). Adding value: learning communities and student engagement. Research in Higher Education, 45(2), 115-138. 